\title{
IMPACT OF PUBLIC HEALTH STRENGTHENING MECHANISM ON OUTCOME AMONG SELECTED AFRICAN COUNTRIES: IMPLICATION ON OUTBREAK IN FRAGILE SSA COUNTRIES.
}

\author{
Asogwa, T. Henry ${ }^{*}$; Ezenekwe, R. Uju²; Ezebuilo, R. Ukwueze ${ }^{3}$; \& Iwuamadi, C. Kelechi ${ }^{4}$ \\ ${ }^{* 1,4}$ Institute for Development Studies, University of Nigeria, Enugu Campus \\ ${ }^{2}$ Department of Economics, Nnamdi Azikiwe University \\ ${ }^{3}$ Department of Economics, University of Nigeria Nsukka
}

*Corresponding Author: -

Email: henry.asogwa@unn.edu.ng

\begin{abstract}
: -
This study is motivated to investigate health impact of Public Health Strengthening mechanism on Outcome among selected African countries: Implication on Outbreak in Fragile SSA countries. Specifically looking at the differences in health impacts among selected SubSaharan African countries considering its implication on covid-19 outbreak. Employing the panel data estimation technique and the World Bank Indicators (WBI) from 2000 to 2019, across the selected Sub-Saharan African Countries we found that among the mechanism that impact on health, Life expectancy, domestic private health expenditure and health expenditure are among the top opportunities for strengthening public health in SSA countries. The result also, showed that major improvement in health care in most SSA countries is greatly financed by external funding, and domestic private health expenditures. Hence, recommended that legislations may be involved to address the issues of public health care with regards to issues that boarders on accountability on health care facilities procurement among SSA countries. Also, aids intervention towards health care should be evaluated from time to time by the funders to minimize the level of public corrupt practices that will lead to aim not been achieved.
\end{abstract}

Keywords: - Public Health, Health Expenditure, Health Outcome, 


\section{INTRODUCTION}

There is no hidden truth to the global public health crisis created by the current Covid-19 pandemic across countries. The outcome on this Pandemic has impacted hugely on countries economy ranging from developed economies to less developed economy yet not much success have been recorded to ameliorate the health crisis challenge. Interestingly, this no doubt is also pushing for a better option of strengthening public health especially for most developing economies. Improving health in developing countries by expanding people's access to health care have attracted serious response as supported by Urama, Ogunleye and Wabiri (2020). In some instances, most countries fiscal health expenditure have revealed the major weakness in the region health system. The covid-19 rising mortality rate across the world added to this by constraining medical tourism as shown in most developing countries in Sub-Saharan regions. The opportunity of the pandemic is supposed to be part of the drivers strengthening disease surveillance in high-risk disease outbreaks and other public health emergencies in most SSA countries if lessons are well taken by leaders of SSA countries. According to Bloland, Simone, Burkholder, Slutsker and Cock (2012) health system strengthening has become a recognized priority for achieving major public health goals such as those identified by disease-specific global health initiatives for HIV/AIDs, tuberculosis, malaria, childhood immunizations, and others. In other word, prioritize strengthening of public health systems in the form of investments that strengthen six key public health functions improves public health outcomes for populations. Part of the concern for SSA countries is not demonstrating concrete achievement in area of preventing disease, reduction of risk of communicable and non-communicable diseases and injuries; ensuring public's access to quality health services as well as sincere responses to health consequences of environmental hazards and natural or manmade disasters aimed at promoting public health behaviors.

This no doubt have also, position the region poorly in terms of rank. For example, WHO report (2020) reveals that South Africa remains the hardest hit country on the African continent and is ranked tenth globally, although with relatively low numbers of deaths though with the spike in number of health worker infections gradually increasing concern. Also, South Africa remains the most affected, with 27360 (63\%) health workers infected, followed by Algeria (2 300), Nigeria (2 175), Ghana (2 065), Ethiopia (1 506), Kenya (1 029), Cameroon (808), Uganda (592), Guinea (513), Mozambique (484), Namibia (464), Equatorial Guinea (363), Senegal (349), Eswatini (291), Guinea-Bissau (282) and Malawi (280). The other 28 countries that have recorded health worker infections are shown in Table 1. Liberia 16.3\% (221/1 354), Niger 15.3\% (184/1 200), Guinea Bissau 12.0\% (282/2 362), Sierra Leone 10.1\% (230/2 277), Sao Tome and Principe 9.6\% (88/914), Mauritius 7.6\% (30/395) and Equatorial Guinea 7.2\% (363/5 052) have the highest country specific proportion of health worker infections among confirmed cases.

Despite these opportunities, strengthening public health capacities and services by mainstreaming health promotion also presents the challenge of preserving the unique identity of health promotion (Broucke, 2017). Since the 2014 Ebola outbreak many public- and privatesector leaders have seen a need for improved management of global public health emergencies. The effects of the Ebola epidemic go well beyond the three hardest-hit countries and beyond the health sector. Education, child protection, commerce, transportation, and human rights have all suffered. The consequences and lethality of Ebola have increased interest in coordinated global response to infectious threats, many of which could disrupt global health and commerce far more than the recent outbreak.

SSA countries faces multiple health challenges despite recent improvements, out of pocket expenditure in health has remain the major health care financing in many parts of the region. Similarly, health inequalities and poor health facilities, corruptions among other factors have remained major constraint to public health improvement in most countries in the region. Several Literature seems to have argued that The level of public sector readiness in tackling global pandemic in sub-Saharan Africa countries have questioned the level of the region health financing gap due to the poor public accountability process.

More even, that SSA countries fiscal plan do not seem to understand how public health is to be at the centre of health improvement or even in the process of been fully integrated to address challenges caused by many other political, economic, environmental and institutional actors whose activities influence health. This continuous attitude account for the regions' public health challenge. However, it is expected that the current pandemic will improve public health operations, capacities and strengthened services across SSA countries. Hence, this study aimed at investigating the differences in health impacts among selected Sub-Saharan African countries. This study will guide policy direction and opportunities for strengthening public health in Sub-Saharan Africa countries.

\section{Literature Review}

Literature across levels have argued that health financing to a large is an essential input to health system designed to provide health access by states at different levels across the globe. This for many studies emanates from the stream of revenue collection, pooling of resources, and interventions among other financing mechanism employed to improve health system operations and performance as in terms of equity, efficiency, and health outcomes across the world.

Anyanwu and Erhijakpor (2009) demonstrates evidence linking African countries' per capita total as well as government health expenditures and per capita income to two health outcomes: infant mortality and under-five mortality. Employing data from 47 African countries between 1999 and 2004 showed how health expenditures have a statistically significant negative effect on infant and under-five mortality rates. The study argued that total health expenditures (as well as the public component) are certainly important contributors to health outcomes. However, that both infant and under-five mortality are positively and significantly associated with Sub-Saharan Africa but not true for North Africa. And that while, ethno linguistic fractionalization and HIV prevalence positively and significantly affect the health outcomes, higher numbers of physicians and female literacy significantly reduce these health outcomes. This account for the level of 
Millennium Development Goals targets in most SSA countries, which ordinarily should have provided opportunities for public health in SSA countries.

Broucke (2017) resolved that, to address health challenges among countries, the need for a reorientation of health services, with a more prominent role for public health and health promotion is required. This is seen where some developed countries establish a 'Coalition of Partners' that will take on the formidable task of strengthening public health capacities and services where huge results have come from. His argument is that poor countries should strengthen public health role, such that is necessary for specific capacities that are needed and of the training facilities, career opportunities, and professional organizational support that must be mobilized to establish these capacities as in the case of Europe and other European Region.

Baker and Koplan (2002) argue that public health attention has been focused on the vital need for a strong public health infrastructure to protect community health and by providing an overview progress during the past decade and point to immediate challenges and opportunities that resulted from recent events highlighted the need for continued vigilance and broad partnership development if we are to maintain public support for public health. Also, point to the need for better language, compelling case reports, and quantitative capacity assessment to guide policymakers and program leaders and to ensure long-term support.

Zwanikken, Alexander and Scherpbier (2016) argued whether training of mid- to higher level cadres in public health prepared graduates with competencies to strengthen health systems in low- and middle-income countries. The study maintained that measuring educational impact has been notoriously difficult; therefore, innovative methods for measuring the outcome and impact of MPH programs were sought. There was considerable impact at many levels; graduates were perceived to be able to contribute significantly to their workplaces and often had influence at the national level. Much of the impact described was in line with public health educational aims. The qualitative method study revealed more indepth understanding of graduates' impact as well as their career pathways.

Kulkarmi (2016) investigated health input, health outcomes and public health expenditure mechanism of emerging economies of BRICS based on the panel data of the five BRICS nations, Brazil, India, China, Russian Federation and South Africa based on regression with fixed effects model. The finding showed positive correlation between health outcome and the GDP Per capita, Adult literacy rate, and Out of Pocket expenditure. Also, that the age dependency ratio shows a positive elasticity with IMR confirming the negative correlation between age dependency relation and health production. Again that the public health expenditure mechanism shows a positive correlation with IMR implying that higher public expenditure indicates higher IMR or lower health outcomes. Arguing further that the efficiency of public expenditure for financing quasi-public goods like education or health is debatable as evidence from the BRICS countries in the present study reinstates that an increase in the size of public health expenditure mechanism alone cannot assure increased health outcome, unless the quality of delivery and finance system is significantly improved.

Bein, Unlucan, Olowu, and Kalifa (2017) investigated the association between healthcare expenditures mechanism and health outcomes for eight East African countries of Burundi, Eritrea, Ethiopia, Kenya, Rwanda, Sudan, Tanzania, and Uganda. Their argument was based on the health outcomes that are linked to improvement in adult life expectancy and a reduction in the number of neonatal, infant and under-five deaths. Adopting both panel data regression and time series techniques with data from WDI 2000 to 2014 and established that there is a strong positive association between total healthcare expenditures mechanism and total life expectancy. Further that healthcare had a stronger effect on improving life expectancy in females than in males while, negative relationship between healthcare expenditures and the number of neonatal, infant, and under-five deaths also exist. Hence, that while it is necessary to allocate resources to public healthcare sector, it will also be better if such consideration is implemented for private health care providers so as to increase health care access for the eight East African countries.

Deaton and Tortora (2017) investigated Sub-Saharan African health status and health financing mechanism using historical data from the Gallup World Poll in 2012 to document sub-Saharan Africans' perceived health status, their satisfaction with health care, their contact with medical professionals, and the priority they attach to health care. The finding showed that in comparison to other regions of the world, sub-Saharan Africa has the lowest ratings for well-being and the lowest satisfaction with health care. Additionally, Sub-Saharan Africans do not prioritize health care as a matter of policy, although donors are increasingly shifting their aid efforts in subSaharan Africa towards health.

According to Bonfrer and Gustafsson-Wright (2017), risks as a central part of life to households in low-income countries where health shocks in particular is associated with poverty have continue to deprive many of them the opportunity to access the best of health care facilities and system. Even when it is formal that most formal financing mechanisms designed to protect households against the financial consequences of health shocks have been largely absent among poor rural households or skewed toward some privileged few. In identifying the relative importance of health shocks as well as the factors associated with coping behavior. This study randomly selected 1226 agricultural households in Kenya. Adopting cross sectional study design and probit model identified the main coping strategies associated with facing a health shock in terms of; savings, assets and gifts or loans. And that illness and injury shocks dominate all other shocks in prevalence as huge percent of households incurred catastrophic health expenditure annually. And that implementing pre-payment or saving mechanisms help protect households against the financial consequences of ill health provides another better option of strengthening public health system in the region.

Ly, Eozenou, Nandakumar, Pablos-Mendez, Evans and Adeyi (2017) assessed sub-Saharan African countries' abilities to afford, and finance their own essential health needs using crosssectional, longitudinal health spending data, and multilevel model with regional and country random effects from the dynamic panel estimation model to demonstrate that some countries still rely on high out-of-pocket or donor spending to finance an essential package of health services. 
Raeesi, Harati-Khalilabad, Rezapour, Azari and Javan-Noughabi (2018) employed econometric method to estimate the effect of health expenditure mechanism on health status linking countries' health expenditures to infant mortality, under5 mortality and life expectancy within 4 different health care systems outcomes. Using Panel data estimation techniques for 25 countries from 2000 to 2015 found that significant relationship was found between health expenditures mechanism and health indicators. The effect of private health expenditures mechanism on health outcomes in countries with mixed health financing system and traditional sickness fund insurance was higher than public expenditures. Also, after comparing the results between different health care systems found that the effect of health expenditure on the health outcome in countries with national health system (NHS) was more than other health care systems. The study argued that since private and public health expenditures have different effects on health outcomes in each health care system, countries should choose an optimal combination of private and public health expenditures mechanism.

Rahman, khanam, and Rahman (2018) investigated the relationship between different types of healthcare expenditures (public, private and total) and three main health status outcomes; life expectancy at birth, crude death rate and infant mortality rate in the region of South Asian Association for Regional Cooperation (SAARC) and Association for South East Asian Nations (ASEAN). Using the World Bank data set for 15 countries from 1995 to 2014 and panel data analysis where relevant fixed and random effect models were estimated to determine the effects of healthcare expenditure mechanism on health outcomes. The finding showed that total health expenditure, public health expenditure and private health expenditure significantly reduced infant mortality rates, and, the extent of effect of private health expenditure was greater than that of public health expenditure. Private health expenditure also had a significant role in reducing the crude death rate. Per capita income growth and improved sanitation facilities also had significant positive roles in improving population health in the region. In addition, the total health expenditure (as a percentage of GDP) and health outcomes in the region of South Asian Association for Regional Cooperation (SAARC) and Association for South East Asian Nations (ASEAN) are lower than that of the OECD region and the world.

Micah, Chen, Zlavog, Hashimi, Chapin, and Dieleman, (2018) argued that Government health spending mechanism is a primary source of funding in the health sector across the world. However, in sub-Saharan Africa, only about a third of all health spending is sourced from the government. Therefore, in investigating determinants and the variation in government health spending across sub-Saharan African countries using panel data on domestic government health spending in 46 countries in Sub-Saharan Africa from 1995 to 2015. The finding showed that while the growth rate in government health spending mechanism in sub-Saharan Africa has been positive overall, there are variations across subgroups. Evidence show that between 1995 to 2015 government healths spending mechanism in West Africa grew by 6.7\%, whereas in Southern Africa it grew by only $4.5 \%$ each year. Furthermore, the results from the decomposition, however, showed that individual country characteristics made up the highest percentage of the explained variation in government health spending mechanism across subSaharan African countries.

Myint, Pavlova, Thein, and Groot (2019) systematically reviewed the health-financing mechanisms, revenue rising, pooling, purchasing, and benefits, in association to Southeast Asian Nations (ASEAN) and the People's Republic of China, and their impact on universal health coverage (UHC) goals in terms of universal financial protection, utilization/equity and quality. Adopting conceptual methodology found that two main source of health care financing mechanism are through direct/indirect taxes and out of pocket payments in all ASEAN countries and China except for Brunei where natural resource revenues are the main source of revenue collection. Brunei, Indonesia, Philippines, Malaysia, and Viet Nam have a single pool for revenue collection constituting a national health insurance. Cambodia, China, Lao, Singapore, and Thailand have implemented multiple pooling systems while Myanmar has no formal arrangement. Capitation, Fee-for-Service, DRGs, Fee schedules, Salary, and Global budget were the methods of purchasing in the studied countries. Although many studies provide evidence of an increase in financial protection after reforming the health-financing mechanisms in the studied countries, yet inequity in financial protection continue to exist. Overall, the utilization of health care among the poor has increased as a consequence of the implementation of government subsidized health insurance schemes which target the poor in most of the studied countries.

Hlafa, Sibanda and Hompashe (2019) investigated the association between public health expenditure mechanism and health outcomes in South Africa's nine provinces from 2002 to 2016. The study implemented fixed effects and a random effects panel data estimation technique to control for time effects and individual provincial heterogeneity. This was followed by employing the Hausman specification test to identify the fixed effects model as the appropriate estimator for the study. The study employed the seemingly unrelated regression (SUR) model and the least squares dummy variable (LSDV) model to examine the impact of public health expenditure on each province separately. The findings elucidated that the relationship between public health expenditure mechanism and health outcomes in South Africa varied across provinces depending on provincial management and infrastructure availability.

Despite the effort of all these studies in health financing mechanism, and health outcome, it's clear that the differences in health impacts among selected Sub-Saharan African countries was yet to be addressed among studies examined. This clearly limits opportunities that could have strengthen public health policy in the first place. Considering the time, the nature of the study methodology which is set to adopt panel estimation technique given its fundamental advantage of great flexibility in modeling differences in behavior across individual countries which none of the studies reviewed could provide by countries across selected Sub-Sahara Africa (SSA) this study therefore, will bridge the gap in the literature by distinguishing this study from every other study already published through its methodology.

\section{Methodology}

Theoretical framework of this study is developed around the Grossman's (1972) model of health as derived demand from the model of optimal control, where health capital is a consumption good as well as an investment good. As such create 
literature connection on how socio-economic inputs such as public health expenditure do not have a direct impact on health outcomes except through proximate determinants that indirectly affects health outcomes. In this context, policies and fiscal plan demonstrates positive impact in strengthening public health. In providing this connection, the choice of Wagner's theory of increasing state spending provides the theoretical framework by establishing how growth of any economy results in an increase in continual introduction of new laws and the development of the legal structure such that continuing increases in public sector expenditure increase structural opportunities for sustained development.

In other words, as economic growth raises income, there will be an increase in demand for education, recreation, and health care. This agrees with the study by Anyanwu and Erhijakpor(2007), Allegri, Saueborn, Kouyate, and Flessa (2009)that government health expenditures mechanism and per capita income have huge and significant implication on health outcomes of infant mortality and under-five mortality in Sub-Saharan Africa. This study therefore, adopts the panel estimation techniques given its fundamental advantage over cross section estimation or perhaps time series data frequencies as it will allows the researcher great flexibility in modeling differences in behavior across countries in estimating the differences in health impacts among selected Sub-Saharan African countries.

To estimates fixed effects, model one is presented as;

$L E_{i t}=\alpha_{1}+\beta_{2}$ dphe $+\beta_{3}$ hexp gdp $+\beta_{4}$ hexpen $+\beta_{5}$ dhepercap $+\beta_{6}$ dggh $\exp +\beta_{7}$ exhea exp $+\beta_{8}$ oophealth $+\beta_{1}$ chexp gdp $+\beta_{10}$ i.SSAcountries $+\phi_{1}+\varepsilon_{i t}$

1

While, to estimate the random effect such that at the point of comparing the two models based on hypotheses, random effects model is specified as;

$L E_{\text {it }}=\alpha_{1}+\beta_{2}$ dphe $+\beta_{3}$ hexp gdp $+\beta_{4}$ hexpen $+\beta_{5}$ dhepercap $+\beta_{6}$ dgghexp $+\beta_{7}$ exhea exp $+\beta_{8}$ oophealth $+\beta_{4}$ chexp gdp $+\beta_{10}$ iSSAcountries $+\phi_{1}+\varepsilon_{2 i t}$

Where; $L E_{i t}=$ Life expectancy (as a proxy for health outcome); $d p h e=$ domestic private health expenditure; $h \exp g d p$ $=$ health expenditure to GDP; hexpen= health expenditure; dhepercap = domestic private health expenditure per capita; dgghexp = domestic general government health expenditure; exheaexp= external health expenditure per capita; oophealth $=$ out - of - pocket expenditure on health $;$ chexpgdp $=$ current health expenditure $\%$ of gdp ;iSSAcountries. $=$ index of selected SSA countries $\beta$ and $\beta=$ parametric coefficients $; \mathrm{t}=$ indexes time component $(2000-2019)$.

$\mathrm{i}=$ indexes, Bostswana, Coted'ivoire, Cameroon, Algeria, Egypt, Ethiopia, Gabon, Ghana, Guinea, Gambia, Guinea Bissau, Equatorial Guinea, Kenya, Liberia, Morocco, Mali,Mozambique, Niger, Nigeria, Rwanda, Senegal, Sierra Leone, Chad, Togo, Tunisia, Tanzania, Uganda, South Africa, Zambia, and Malawi, $(n=30)$.

We assume that individual error components are uncorrelated with each other and are not auto correlated (across both cross-section and time-series units).

Adopting a conventional random effect approach, the usual assumption are that the individual random effects $\beta \beta(0, \beta$ the observed time-varying errors $\beta$ iid $\left(0, \beta^{2} \mathrm{E}\right)$; the $\beta_{1}$ and $\square_{\mathrm{it}}$ are independent for all $\mathrm{i}$ and $\mathrm{t}$ and the stochastic variables $\mathrm{X}_{\mathrm{it}}$ are strictly exogenous with respect to $\beta$ and $\mathrm{v}$ : $\operatorname{Cov}\left(\beta, \mathrm{X}_{\mathrm{it}}\right)=0, \operatorname{Cov}\left(\beta_{\mathrm{it}} \beta \mathrm{X}_{\mathrm{it}}\right)=0$ for all $\mathrm{i}, \mathrm{j}$ and $\mathrm{t}$.

Where $X_{\mathrm{it}}=\beta$ and $\beta$

Apriori Expectation

$\beta<0, \beta_{i t}<0$

The study adopted the Hausman statistical test to select the most appropriate model between Fixed Effect and Random Effect model using the criterion selection:

$\mathrm{H}_{0}$ : Select RE ( $\left.>>0.05\right)$

$\mathrm{H}_{1}$ : Select FE $(\mathrm{p}<0.05)$

The study adopted secondary data from the World Bank Indicators (WBI) 2019. The data frequency covered from 2000 to 2019, across the selected Sub-Saharan African Countries. STATA 13 analytical tool was used for the data analysis. 


\section{Result of Findings}

Table 4.1: Panel Descriptive Analysis

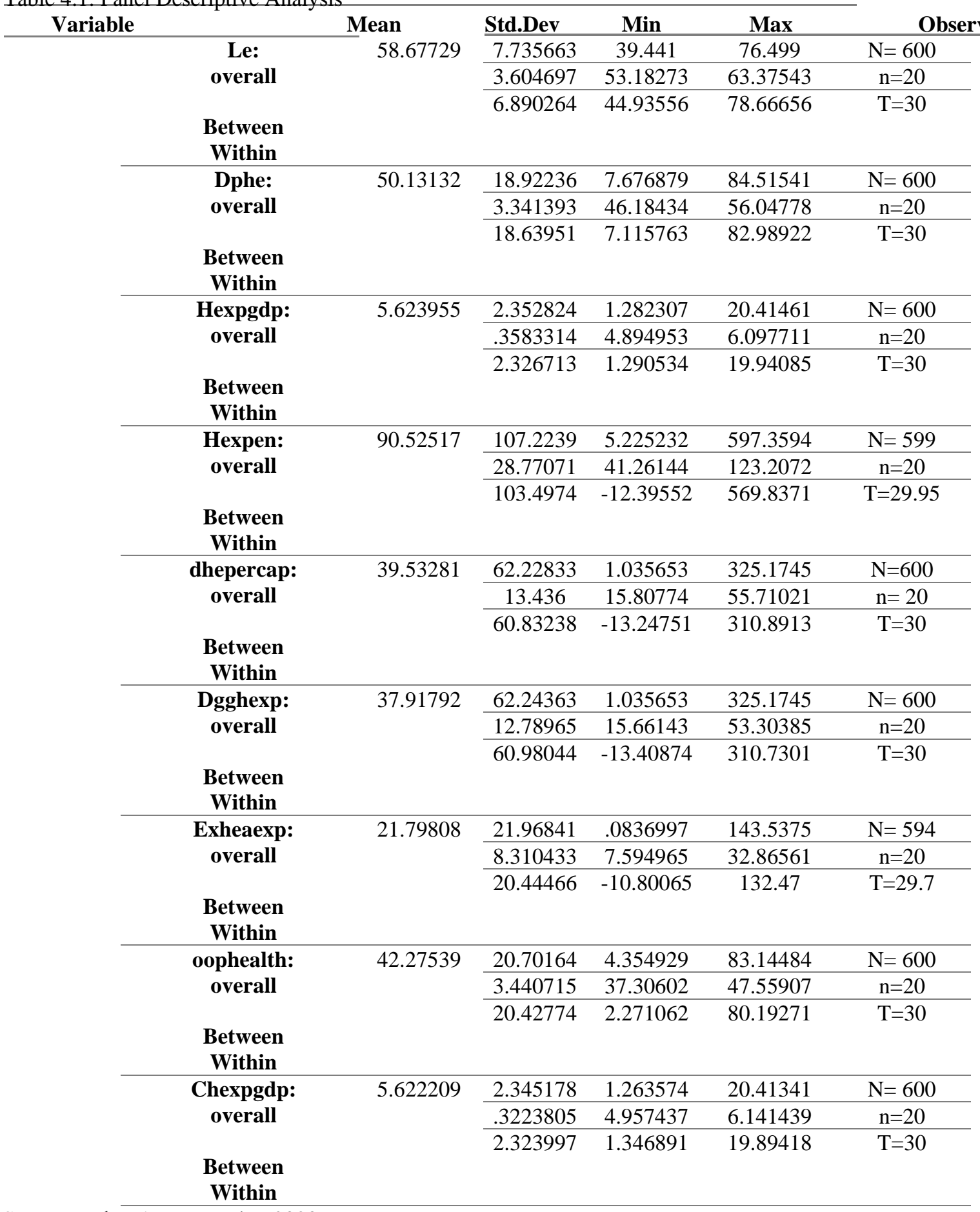

Source: authors' computation 2020.

The result from the panel result in table 4.1 showed that on the average opportunities for strengthening public health can affects Life expectancy which was used to measure health impact and it accounts for 58.7 per cent among selected SSA countries. This is also similar to domestic private health expenditure(dphe) which accounts for 50.1 per cent, health expenditure to gdp (hexpgdp) at 5.6 per cent, health expenditure(hexpen) at 90.5 per cent, domestic private health expenditure per capita(dhepercap) at 39.5 per cent, domestic general government health expenditure(dgghexp) at 37.9 per cent, external health expenditure(exheaexp) at 21.8 per cent, out of pocket expenditure on health (oophealth) at 42.3 per cent and current health expenditure $\%$ of gdp (chexpgdp) at 5.6 per cent.

The findings clearly reveals that among these mechanisms that impact on health, Life expectancy, domestic private health expenditure(dphe) and health expenditure(hexpen) are among the top opportunities for strengthening public health among SSA countries. 
Table 4.2: Panel Fixed Effects Result

\begin{tabular}{|c|c|c|c|}
\hline Le: & Coef. & $\mathbf{T}$ & $\mathbf{P}>|\mathbf{t}|$ \\
\hline dphe & 0.0512813 & 2.76 & 0.006 \\
\hline hexpgdp & -0.4632505 & -2.55 & 0.011 \\
\hline hexpen & -0.0184163 & -4.13 & 0.000 \\
\hline dhepercap & 0.0526431 & 3.40 & 0.001 \\
\hline dgghexp & -0.0349056 & -2.07 & 0.039 \\
\hline exheaexp & 0.0833095 & 12.53 & 0.000 \\
\hline oophealth & -0.0210362 & -1.03 & 0.305 \\
\hline chexpgdp & 0.1958848 & 1.07 & 0.285 \\
\hline \multicolumn{4}{|l|}{$\begin{array}{l}\text { IdBotswana (base } \\
\text { category) }\end{array}$} \\
\hline 2. Cote d'Ivoire & -5.756842 & -5.97 & 0.000 \\
\hline 3. Cameroon & -3.148739 & -2.75 & 0.006 \\
\hline 4. Algeria & 19.10895 & 24.03 & 0.000 \\
\hline 5. Egypt & 12.91278 & 12.25 & 0.000 \\
\hline 6. Ethiopia & 2.132514 & 2.21 & 0.027 \\
\hline 7. Gabon & 5.141387 & 6.72 & 0.000 \\
\hline 8. Ghana & 2.319385 & 2.34 & 0.020 \\
\hline 9. Guinea & -3.153078 & -2.94 & 0.003 \\
\hline 10.Gambia & .8551857 & 0.88 & 0.382 \\
\hline 11.Guinea Bissau & -3.463483 & -3.29 & 0.001 \\
\hline 12.Equatorial Guinea & -1.318447 & -1.21 & 0.225 \\
\hline 13.Kenya & -1.669847 & -1.53 & 0.126 \\
\hline 14.Liberia & .2401634 & 0.22 & 0.829 \\
\hline 15.Morocco & 17.41164 & 18.12 & 0.000 \\
\hline 16.Mali & -3.972372 & -3.69 & 0.000 \\
\hline 17.Mozambique & -4.394457 & -4.42 & 0.000 \\
\hline 18.Niger & -.8400774 & -0.76 & 0.446 \\
\hline 19.Nigeria & -8.581482 & -6.83 & 0.000 \\
\hline 20.Rwanda & 1.461308 & 1.61 & 0.107 \\
\hline 21.Senegal & 6.095799 & 5.84 & 0.000 \\
\hline 22.Sierra-Leone & -9.976632 & -7.77 & 0.000 \\
\hline 23.Chad & -7.202199 & -6.69 & 0.000 \\
\hline 24.Togo & -.9997214 & -0.92 & 0.359 \\
\hline 25.Tunisia & 19.98592 & 23.68 & 0.000 \\
\hline 26.Tanzania & -1.060535 & -1.10 & 0.272 \\
\hline 27.Uganda & -2.946952 & -3.01 & 0.003 \\
\hline 28.South Africa & 3.278475 & 4.60 & 0.000 \\
\hline 29.Zambia & -5.706269 & -6.75 & 0.000 \\
\hline 30.Malawi & -4.398145 & -4.60 & 0.000 \\
\hline _cons & 56.89602 & 55.42 & 0.000 \\
\hline Rho stat $=0.82810662$ & $\begin{array}{c}\mathrm{F}(19,536)= \\
63.46\end{array}$ & $\begin{array}{c}\text { Prob }>F= \\
0.0000\end{array}$ & $\begin{array}{c}\text { R-sq: } \\
\text { within }=0.9534 \\
\text { Between }=0.8990 \\
\text { Overall }=0.7816\end{array}$ \\
\hline
\end{tabular}

Source: authors' computation, 2020

From the estimated result, the pre-estimation test of the panel result showed the necessity of the Hausman's test to determine the most appropriate technique based on the criterion selection such that fixed effect estimation will be accepted when prob $>$ chi $2<0.05$, or accepting random effect estimation technique when prob> chi $2>0.05$. By Accepting $\mathrm{H}_{1}$ : and rejecting $\mathrm{H}_{0}$ : by implication showed that fixed effect model was applied as most appropriate for this analysis. 
The result from the panel data model in table 4.2 showed that domestic private health expenditure(dphe), health expenditure to gdp(hexpgdp), health expenditure(hexpen), domestic private health expenditure per capita(dhepercap),domestic general government health expenditure(dgghexp) and external health expenditure(exheaexp) had both positive and negative significant relationship with health impact among selected Sub-Saharan African countries except for out of pocket expenditure on health (oophealth) and current health expenditure \% of gdp(chexpgdp) that had no significant relationship on health impact among countries in the region. Interestingly, the result revealed that domestic private health expenditure (dphe) had increased health impact significantly by 51 per cent. Similarly, findings also show that domestic private health expenditure per capita (dhepercap) had also significantly increased health impact by 53 per cent as well as external health expenditure (exheaxp) by 83 per cent.

This findings showed that major improvement in health care in most SSA countries is greatly financed by external funding, and domestic private health expenditures which showed significant impact on health impact. With the Covid-19 incidence, it is obvious to show that not much public investment have reflected on public health challenges especially the covid-19 negative health effects. This accounts for some of the reasons for public health facility deficits making it difficult for huge testing capacity in Nigeria and many other African countries.

The health expenditure to gdp (hexpgdp) though significant have negative relationship to health impact among selected SSA countries, this is also, noticed among health expenditure, and domestic private health expenditure per capita. This significant but negative correlation between spending on health among SSA countries and health impact demonstrates the burden of health problems outside the huge external and private budget that cover medical expenditures as revealed in the result. This clearly, analyzes the lost opportunities for strengthening public health system as the covid-19 incidence have shown in most SSA countries especially, with regards to testing capacities, failures of trusting public pronouncement on preventive health measures, abuse on safety measures, rural myth on corona virus as sickness of the elite among others all relating to the failure of public health system in most SSA countries. The Prob> F of 0.000 suggests that the overall model is significant hence the study can conclude that the mode is robust and the results thereof are reliable. While the rho statistics tells us that $83 \%$ of the variance is due to difference across panel.

However, treating Botswana as the base category, the findings also show that countries like Algeria, Egypt, Ethiopia, Gabon, Ghana, Morocco, Senegal, Tunisia, and South Africa have also had positive and statistically significant coefficient showing that on the average their public health mechanism had increased these countries health outcomes respectively when compared to Botswana as evidenced in the t-value statistics that is higher that than 2 (1.96) with a probability value that is less than 0.05 hence significant at $5 \%$ significant level among these countries.

In contrast, countries like Cote d'Ivoire, Cameroon, Guinea, Guinea Bissau, Mali, Mozambique, Nigeria, Sierra-Leone, Chad, Uganda, Zambia, and Malawi interestingly, demonstrates statistically significant coefficient but showed negative impact on health impact or outcome among these countries. In other words, the opportunities for strengthening public health in these countries have yielded negative impact on public health outcomes among identified countries'. This is also evidence in the covid-19 incidence in these countries.

\section{Conclusion, \\ Implication and Recommendations}

The level of public sector readiness in tackling global pandemic in Sub-Saharan Africa countries have questioned the level of region health financing gap due to the poor public accountability process. This motivated the investigation of health impact and opportunities for strengthening public health, specifically looking at the differences in health impacts among selected Sub-Saharan African countries considering its implication on covid-19. Employing the panel data estimation technique and the World Bank Indicators (WBI) from 2000 to 2019, across the selected Sub-Saharan African Countries found that among the mechanism that impact on health, Life expectancy, domestic private health expenditure (dphe) and health expenditure (hexpen) are among the top opportunities for strengthening public health among SSA countries. The result also, showed that major improvement in health care in most SSA countries is greatly financed by external funding, and domestic private health expenditures.

This implies to a large extent reasons why most of the SSA countries continue to hope on interventions, aids and donations before embarking on impactful health programs as noticed during the first incidence of covid-19 pandemic as it was difficult for many countries due to testing capacity, health facility deficits, man power constraint and poor standard health care. Hence, this study recommend that legislations may be involved to address the issues of public health care with regards to issues that boarders on accountability on health care facilities procurement among most SSA countries. There is urgent need for funder's evaluation of specified aids towards health care intervention so as to maintain initial health objectives considering the level of public corrupt practices limiting certain health care opportunities among SSA countries as part of the process to be initiated.

\section{References}

[1].Anyanwu, J.C. and Erhijakpor, A.E.O. (2009). Health Expenditures and Health Outcomes in Africa. African Development Review, 21(2), 400-433.

[2].Baker, E.L., and Koplan, J.P. (2002). Strengthening The Nation's Public Health Infrastructure: Historic Challenge, Unprecedented Opportunity. Health Affairs, 21(6), 15-27.

[3].Broucke, S.V. (2017). Strengthening public health capacity through a health promotion lens. Health Promotion International, 32(5), 763-767.

[4].Bloland, P., Simone, P., Burkholder, B., Slutsker, L., and De Cock, K.D. (2012). The Role of Public Health Institutions in Global Health System Strengthening Efforts: The US CDC's Perspective. PloS Med, 9(4), e1001199. 
[5].Bein, M., Unlucan, D., Olowu, G., and Kalifa, W. (2017). Healthcare spending and health outcomes: evidence from selected East African countries. Journal of African Health Sciences, 17(1), 247-254.

[6].Bonfrer, I. and Gustafsson-Wright, E. (2017). Health shocks, coping strategies and foregone healthcare among agricultural households in Kenya. Journal of Global Public Health, 12(11), 1369-1390.

[7].Deaton, A.S. and Tortora, R. (2017). People in Sub-Saharan Africa Rate Their Health and Health Care Among Lowest in World. Journal of Health Affiliations, 34(3), 519-527.

[8].Durairaj, V., and Evans, D.B. (2010). Fiscal space for health in resource-poor countries. World Health Report Background Paper, No 41.

[9].Gautier, L. and Ridde, V. (2017). Health financing policies in Sub-Saharan Africa: Government Ownership or Donors' influence? A Scoping Review of Policy making Processes. Global Health Research and Policy, 2(23).

[10]. Gouda, H.N., Charlson, F., Sorsdahl, K., Ahmadzade, S., Ferrari, A.J., Erskin, H., Leung, J., Santamauro, D., Lund, C., Aminde, L.N., Mayosi, B.M., Kengne, A. P., Harris, ., Achoki, T., Wiysonge, C., Stein, D.J. andWhiteford, H. (2019). Burden of noncommunicable diseases in sub-Saharan Africa. The Lancet Global Health, 7(10), 13751387.

[11]. Hlafa, B. Sibanda, K. and Hompashe, D.M. (2019). The Impact of Public Health Expenditure on Health Outcomes in South Africa. International journal of Environment research and Public Health, 16(6):2993.

[12]. Lu, C., Schneider, M.T., Gubbins, P., Leach-Kemon, K., Jamison, D. and Murray, C.J. (2010). Public Financing of Health in Developing Countries: A Cross-National Systematic Analysis. The Lancet, 375(9723):1375-1387.

[13]. Micah, A.E., Chen, C.S., Zlavog, B.S., Hashimi, G., Chapin, A., and Dieleman, J.L. (2018). Trends and drivers of government health spending in sub-Saharan Africa, 1995-2015. BMJ Global Health, 4(1).

[14]. Myint, C, Pavlova, M., Thein, K., and Groot, W. (2019). A systematic review of the healthfinancing mechanisms in the Association of Southeast Asian Nations countries and the People's Republic of China: Lessons for the move towards universal health coverage. 14(6): e0217278.

[15]. Kulkarmi, L. (2016). Health Inputs, Health Outcomes and Public Health Expenditure: Evidence from the BRICS Countries. International Journal of Applied Economics, 31(1); 72-84.

[16]. Raeesi, P., Harati-Khalilabad, T., Rezapour, A., Azari, S., and Javan-Noughabi, J. (2018). Effects of private and public health expenditure on health outcomes among countries with different health care systems: 2000 and 2014. Medical Journal of the Islamic Republic of Iran, 32(35).

[17]. Rahman, M.M., khanam, R., and Rahman, M. (2018). Health care expenditure and health outcome nexus: new evidence from the SAARC-ASEAN region. Globalization and health, 14(133).

[18]. Urama, K.C., Ogunleye, E.K., and Wabiri, N. (2020). Policies for Inclusive Health in Post COVID -19 Africa: Summary Outcomes of the African Development Institute (ADI) Global Community of Practice (G-CoP) e-Seminar. African Development Bank Group, June 22-23, 2020.

[19]. Zwanikken, P.A.C., Alexander, L., and Scherpbier, A. (2016). Impact of MPH programs:

[20]. contributing to health system strengthening in low- and middle-income countries?Human Resources for Health, 14(52), 1-19. 